\title{
Oficina de formação continuada em Teatro: as adversidades provenientes do sistema político educacional
}

Rafaela de Mattos Mileni Vanalli Roéfero Amanda Dias Saldan

Recebido: 18/08/2018 Aprovado: 06/11/2018 
Este artigo algumas reflexões acerca dos resultados de uma oficina de formação continuada em Teatro realizada com professoras que atuam com a educação infantil em um município do norte do Paraná. A partir dos relatos apresentados pelas professoras participantes e das observações realizadas, identificamos a importância da formação continuada para os docentes. Por essa razão, o objetivo deste artigo é identificar, partindo dos relatos da oficina, algumas das deficiências em nossas políticas públicas no que se refere à formação, analisando a interferência das mesmas no processo de formação continuada. Como objetivos específicos, buscamos: discutir sobre a postura pela busca de soluções imediatistas e alguns comportamentos, por vezes, defensivo apresentado pelas participantes durante a realização do curso; identificar e por em discussão algumas das legislações vigentes da educação no que se refere às projeções para a formação continuada no Brasil. Os principais autores trazidos para a essência das discussões apresentadas são do campo das Artes Cênicas, em especial, do Teatro Educação. Utilizamos Spolin, 2010; Ryngaert, 2009; Slade, 1978; Sardelich, 2001; Dias, 2014; entre outros.

Palavras-chave: formação continuada; teatro; educação.

\section{INTRODUÇÃO}

As inquietações que originaram este artigo decorrem das observações realizadas durante a oficina de formação continuada em teatro aplicada à professoras que atuam com a educação infantil em um município do norte do Paraná. Antes de tudo, é importante visar que grande parte das participantes, exceto um, eram mulheres. Deste modo, ao tratarmos do coletivo, utilizaremos o gênero feminino.

A oficina ocorreu às sextas-feiras, entre os dias 06 e 28 de Abril, totalizando quatro encontros de 4 horas cada, com dois grupos de educadoras, um no período da manhã e outro no período da tarde, completando sessenta participantes. Como o planejamento realizado se deu da mesma forma em ambas as turmas e as reflexões geradas em cada uma delas são 
complementares, optamos por acoplar os grupos e referirmo-nos a eles de maneira conjunta.

Esta mesma proposta de oficina já havia sido realizada anteriormente, em outros formatos, para públicos distintos, tendo resultado considerados satisfatório'. Posteriormente, as autoras deste artigo foram convidadas, pelas representantes da Secretaria da Educação do município em questão, para ministrar o curso voluntariamente a professores de seus centros de educação infantil. Essa parceria surgiu por intermediação de um dos projetos do programa PIBID de uma universidade também da região norte do Paraná. Por meio da coordenação do projeto foi estabelecida contato com a Secretaria de Educação para a viabilização da proposta aqui apresentada. Isso porque, em princípio, esta era uma das ações vinculadas ao projeto PIBID, em uma de suas frente: formação de professores. O objetivo da oficina era apresentar metodologias possíveis para o trabalho teatral a partir de jogos e discutir sobre os benefícios da sua inserção em sala de aula, a saber: capacidade de desenvolver trabalho em grupo, senso crítico, comunicação, tomada de decisão, diálogo, escuta, respeito, improvisação, coordenação motora e afins. Como o passar das diferentes experiências a proposta tomou corpo e foi replanejada para atender a demanda de formação inicial em Teatro para professores que atuam na educação infantil.

Adentrando na proposta do curso ofertado, o dividimos em três categorias de jogo, com público alvo, tema e autores e autora distintos, que são: a primeira, de jogo dramático infantil, guiada pelo autor Peter Slade que enfatiza a importância da realização do jogo dramático como uma forma "da criança pensar, comprovar, relaxar, trabalhar, lembrar, ousar, experimentar, criar e absorver" (1978, p. 17-18), desde a mais tenra idade até a adolescência; a

\footnotetext{
${ }^{1}$ A primeira realização da oficina se deu em formato reduzido (4h) e foi para o grupo do Programa Institucional de Bolsas de Iniciação à Docência (PIBID) ao qual as autoras pertenciam. Entre os participantes, estavam estudantes de Música e Artes Cênicas. A segunda aplicação da oficina se deu em um Encontro de Licenciaturas, na UNISINOS RS, também em formato reduzido. Participaram estudantes de teatro, música, biologia e pedagogia.
} 
segunda, de práticas coletivas com jogos dramáticos e teatrais, embasada por Viola Spolin e Jean Pierre Ryngaert que revela o jogo como possibilidade vantajosa para qualquer praticante, sejam atores ou não atores; o foco dos autores e, consequentemente, da categoria, está no olhar para os benefícios desenvolvidos pelo exercício e não no resultado final. Por fim, a terceira e última categoria é a dos jogos politizados, tendo como base o brasileiro Augusto Boal, que desenvolveu teorias e metodologias que uniam a prática artística ao debate político, visando a emancipação política e social do sujeito. A mesma finaliza a formação no intuito de apresentar discussões possíveis por meio do teatro e também como forma de provocar o olhar crítico e reflexivo das educadoras a respeito da sua função, do ambiente de trabalho e das políticas que regem a docência. Assim, a intenção da oficina era que, por meio das categorias, os participantes pudessem conhecer teorias e propostas práticas de autores distintos e refletir a respeito de cada uma delas.

Durante as discussões na oficina notamos diversos comportamentos das participantes que destoavam do "esperado" (tendo em vista que eram docentes trabalhando com arte de maneira direta e indireta), como a busca constante por materiais prontos, a dificuldade e o receio de compreender a prática teatral e a postura contraditória enquanto alunas. Cada dificuldade encontrada nos motivou a tentar compreender, de modo sistemático, os seus fatores, que nos levavam a crer, a princípio, que advinham de um sistema político e social que desvaloriza os educadores e a profissão docente. Sendo assim, o artigo visa identificar esses problemas e discuti-los, para que possamos perceber o impacto dessas falhas na formação continuada (neste caso, em teatro) e repensar meios de modificá-los.

Essa análise será feita a partir de uma revisão bibliográfica, utilizando os relatórios das práticas realizadas com as professoras da educação infantil e dialogando as legislações vigentes com materiais bibliográficos referentes à pedagogia teatral, de modo a identificar as lacunas existentes entre a teoria e prática. 


\section{OS DESDOBRAMENTOS DA OFICINA DE FORMAÇÃO CONTINUADA EM TEATRO COM O GRUPO DE PROFESSORAS DOS CMEIS}

O grupo participante da oficina era composto por professoras atuantes nos primeiros anos da educação infantil, abrangendo crianças de 0 a 5 anos de idade. Segundo relatos das participantes, a formação inicial da maioria era o magistério e a pedagogia. Todo o grupo de participantes atuava na educação infantil. A divulgação da oficina ficou sob responsabilidade da própria Secretaria da Educação, então não esteve sob nosso domínio o conhecimento dos critérios de chamamento, mas soubemos, superficialmente, por meio dos relatos de algumas professoras, que esse convite se deu por parte de um membro da Secretaria da Educação, advogando em favor dos benefícios que essa experiência poderia trazer ao trabalho em sala de aula com as crianças.

Em um primeiro momento, ao levantarmos questões relacionadas à presença da linguagem teatral nas práticas com as crianças, recebemos a resposta de que não havia abordagem teatral nos trabalhos que elas realizavam na escola. No entanto, as participantes afirmaram que o jogo fazia parte da vivência escolar das crianças, por meio da música ou da própria brincadeira.

A estrutura da oficina continha uma abordagem prática. As professoras participavam dos jogos, a fim de possibilitar vivências com as práticas teatrais propostas. Posteriormente, apresentávamos e discutíamos os conceitos teatrais que estavam na base estrutural de cada uma das dinâmicas. Todos os materiais usados, tanto para a realização das práticas, quanto de suporte teórico, correspondiam aos estudos dos seguintes autores: Peter Slade (1912 - 2004), Viola Spolin (1906 - 1994), Jean-Pierre Ryngaert (1914 - 2007) e Augusto Boal (1931 - 2009). Eles foram organizados em três categorias: Jogo Infantil, Jogos de Improvisação e Jogos como dispositivo para emancipação.

A estrutura dos planejamentos para cada encontro semanal continham: alongamento coletivo; jogo de aquecimento; jogo dramático introdutório (para trabalhar energia e/ou foco); jogos 
diversos voltados a cada tema, de acordo com a abordagem/autor cerne do encontro; e roda de conversa, para obter o feedback das participantes e discutir as teorias que antecedem tais práticas. No primeiro encontro da oficina, as práticas se voltaram à estrutura do jogo dramático, de acordo com os estudos do autor Peter Slade², possibilitando que o início da oficina se desse de forma amena. Já no segundo encontro, com o início da abordagem de atividades propostas pela autora Viola Spolin, que usa da improvisação como meio de desenvolver a espontaneidade do grupo, algumas professoras hesitaram em participar de atividades, pois estas envolviam jogadores e plateia (Jogos Teatrais). Compreendemos este comportamento, já que possivelmente a oficina foi um dos primeiros contatos das professoras com as propostas teatrais e demandaria maior tempo de vivência para as mesmas se habituarem com as práticas.

Jean-Pierre Ryngaert, um dos autores da segunda categoria de jogo, prevê alguns comportamentos possíveis no jogo, sendo eles positivos ou negativos. Para ele, este receio de jogar chamase inibição e

[...] é uma dificuldade familiar ao jogador iniciante, talvez a mais comum. Comodamente definida como um 'bloqueio', ela se traduz, sobretudo, por uma impossibilidade de superar a angústia causada pelo olhar do outro ou o sentimento de ser ridículo a seus próprios olhos (RYNGAERT, 2009, p. 45).

Deste modo, o autor afirma que o mediador da oficina deve se atentar ao tempo do grupo, mantendo-se paciente com as atitudes iniciais dos participantes. Porém, como o nosso objetivo formativo é o de passar por um percurso de aprimoramento de educadores, investimos em jogos que se equilibravam entre propostas iniciantes e avançadas da prática teatral.

Com o encaminhamento das práticas desenvolvidas, o grupo apontou que alguns dos jogos realizados eram semelhantes aos trabalhados no cotidiano escolar e não eram nomeados

\footnotetext{
${ }^{2}$ A ordem de realização das categorias foi estabelecida considerando também o processo de desenvolvimento das educadoras participantes, visto que se torna mais didático um caminho iniciado por meio de jogos tradicionais e seguidos de jogos que visem o coletivo e que, de pronto, não proponham ao grupo a experiência da exposição e da relação com a plateia.
} 
como um fazer teatral, visto que este é vinculado à concepção de contemplação, apresentações, cenas, homenagens e afins. Identificamos, neste momento, um equívoco conceitual, que nos fez compreender que o termo jogo teatral, ou seja, aquele que contém a presença de um grupo improvisando no espaço de jogo e uma plateia que assiste a ação (SPOLIN, 2010) aparentemente não é apresentado na escola com essa nomenclatura técnica.

Ainda assim, a prática de jogos dramáticos, ou seja, aqueles que envolvem o grupo em uma única ação e que todos atuam simultaneamente (SLADE, 1978) aproximou-se, diversas vezes, do repertório do grupo que traziam comentários como "essa brincadeira já foi feita na turma, mas o formato era diferente" ou "esse jogo me lembra muito aquela brincadeira que as crianças gostam" etc. A partir desses comentários, percebemos que o jogo teatral não está tecnicamente atrelado ao repertório e à prática das docentes, mas o jogo dramático infantil está.

Ao longo do curso, foram observados em alguns momentos uma aparente falta de concentração, desinteresse e certos tipos de desordem, identificados por algumas das reações diante das proposições de atividade encaminhadas pelos ministrantes da oficina. Interessante observar que estes comportamentos são os mesmos adotados pelos alunos em sala de aula e que são veementemente repreendidos pelos professores, em seu próprio discurso. No caso desta oficina, eram professoras, portanto, que estavam reproduzindo o comportamento do qual elas mesmas reclamavam enquanto docentes.

Esta conduta não inviabilizou a realização da oficina tal como foi planejada, mas gerou a reflexão não só na equipe ministrante, mas nas participantes também, visto que uma professora, após uma atividade agitada, assumiu que elas estavam se assemelhando aos alunos que repreendem. Essas atitudes relacionadas ao "mau" comportamento foram detectadas ao longo de toda a oficina e, em cada momento desse, tentávamos orientar a retomar a concentração.

Tais reações por parte das professoras participantes se tornaram mote para importantes questionamentos e reflexões posteriores. 


\section{A RELEVÂNCIA DAS PRÁTICAS TEATRAIS EM SALA DE AULA}

Uma das constatações encontradas a partir da observação do comportamento das professoras participantes foi a busca por materiais passíveis de reprodução nos seus espaços de trabalho. Como foi apresentada, a estrutura da oficina não se objetiva na prática de jogos na educação infantil, mas busca abranger uma série de leituras a respeito da prática teatral por meio de jogos e a sua aplicabilidade no espaço escolar em diversos níveis de ensino. Contudo, a mesma foi realizada com professoras dos centros de educação infantil e foi perceptível a resistência e a desvalorização do grupo diante de jogos que, segundo elas, não eram cabíveis de serem trabalhados com crianças.

Essa concepção instrumentalizadora da arte também foi observada por Sardelich (2001, p. 150), ao pontuar que esse equívoco ocorre "[...] pois entendem-na [a arte] como atividade auxiliar, recreativa, como meio para alcançar outros fins e não pelos valores que ela possui em si mesma". Dias menciona um relato semelhante, visto que "[...] ao considerarmos o contexto de trabalho dos professores com as crianças e mesmo da formação continuada, é comum que a ideia de transmissão seja tomada como ação que faz passar algo, quase que automaticamente, de um sujeito a outro" (2014, p. 20), ou seja, percebemos que, mesmo aqueles professores que se disponibilizam para as práticas de formação continuada (o que pressupõe compreender o conhecimento em constante transformação), demonstram estar à espera de uma metodologia prescritiva e infalível.

Apesar do erro se manifestar na fala do professor, ele é resultado de uma série de fatores, advindos de dimensões superiores à própria prática docente. Sardelich nos mostra que "É como se a escola só se interessasse pelo saber usar e não pelo saber fazer" (2001, p. 146) e essa identidade adotada pela escola é reflexo, ainda, da camada superior: "Os sistemas com administração centralizada [...] demonstram uma atitude 
na qual predomina a heteronomia sobre a autonomia" (2001, p. 146). Ou seja, o problema manifesto pelo docente em sala de aula é produto da orientação do próprio colégio que, por sua vez, está seguindo a identidade metodológica e política adotada pelas instâncias superiores.

Além disso, existem outros procedimentos extremamente prejudiciais à qualidade do ensino ofertado nas escolas, quais sejam: falta de incentivo à formação continuada e ao aperfeiçoamento docente (SARDELICH, 2001), escassez de recursos e ambientes adequados, carga horária excessiva, poucas horas para estudo e planejamento, etc (SCHEIBE, 2010).

Um dos problemas considerados por Cruz e Lüdke (2005) em relação a atuação desses profissionais, diz respeito à própria formação. Segundo as autoras, os cursos de licenciaturas se estruturam a partir da separação entre os conteúdos pedagógicos (didática, por exemplo) e os conteúdos básicos das disciplinas específicas da área. Deste modo, ocorre uma dicotomia entre os que se caracterizam por serem específicos e/ou pedagógicos. Ou seja, ao se ensinar o Renascimento, por exemplo, prima-se pela apresentação dos conteúdos que envolvem este período histórico, deixando em segundo plano a maneira de ministrá-lo. De acordo com as autoras, isso se deve ao fato de haver uma diferença entre os docentes responsáveis por essas disciplinas no ensino superior que são formados, em sua maioria, em cursos bacharéis.

No entanto, salientamos que uma das características imprescindíveis à atuação do educador é a de sempre buscar o conhecimento e estar atento às transformações que ocorrem em níveis históricos e geográficos, em prol tanto do seu próprio reconhecimento enquanto sujeito como em prol de melhorias em nível profissional. Deste modo, Sardelich (2001, p. 141) afirma que o educador deve assumir a sua posição de sujeito incompleto e buscar conhecimentos que ultrapassem a sua formação inicial. Ou seja, este profissional deve se destacar pelo comprometimento com as atividades que se propõe a realizar, buscando uma atualização da própria prática docente. 
Dias destaca que a formação continuada visa o "[...] reconhecimento do desconhecido como possibilidade de produzir sentido" (2014, p. 17). Por esta razão, a oficina ministrada se configurou com uma abordagem teórico-prática pela perspectiva de que os professores devem experienciar cada proposta, participando ativamente do processo formativo. Da mesma forma, a experiência efetiva possibilita a identificação do fazer teatral e o reconhecimento do mesmo em meio às práticas escolares não denominadas como tal.

Deste modo, a ideia da formação continuada buscou suprir essa necessidade ao estimular o aprendizado de conteúdos que dialoguem com o espaço de atuação do professor; ampliar a compreensão acerca da importância do teatro nos espaços de ensino e discutir o papel reflexivo e crítico do educador, rompendo com a prática da reprodução de materiais e com o isolamento dos conteúdos.

O primeiro tópico relaciona-se à possibilidade de os jogos dramáticos e teatrais enriquecerem o repertório dos profissionais, pois realiza uma discussão que amplia a valorização e os objetivos das atividades. Os meios didáticos para atuar em sala de aula são flexíveis e o objetivo da formação é apresentar recursos para que os professores e as professoras conduzam o processo de ensino-aprendizagem de forma menos rígida.

Ao segundo tópico, trazemos a seguinte reflexão: tendo em vista que a área de atuação das profissionais que acompanhamos no decorrer deste trabalho não se volta ao fazer teatral, entendemos a insegurança apresentada pelo grupo ao experienciar essa linguagem. Como citado anteriormente, essas práticas já se faziam presentes no cotidiano das docentes de forma indireta, e conhecer o trabalho teatral sistematizado por autores e autora, por meio de práticas seguidas de materiais e discussões teóricas, pode vir a contribuir com a desmistificação do teatro na escola.

Por fim, o último tópico tornou-se central nas discussões posteriores às práticas referentes às propostas do autor 
Augusto Boal. Para as professoras participantes, reflexões sobre a profissão docente, bem como sobre as políticas que estruturam a educação brasileira, são determinantes para que possam questionar e participar ativamente do sistema político. "O teatro é uma forma de conhecimento e deve ser também um meio de transformar a sociedade" (BOAL, 2015, p. 15). Por isso que a categoria dos jogos de Boal foi tão providencial: ajudou a enriquecer a reflexão a respeito da importância do pensamento crítico na docência.

\section{A IMPORTÂNCIA DAS POLÍTICAS PÚBLICAS PARA A FORMAÇÃO CONTINUADA}

Os programas de formação continuada possuem grande significado no campo da docência. Entende-se que os professores e as professoras, na sua função de educadores, precisam manter seus estudos ativos a fim de atualizar e aperfeiçoar a sua prática na sala de aula. Rangel e Pletitsch (2012) entendem que o processo de formação desses profissionais deve ser compreendido de forma única, não fragmentada, ou seja, a formação continuada pertence ao processo formativo como um todo e deve estar relacionada à formação inicial.

Além disso, a formação continuada tem função importante no que diz respeito à atualização dos conteúdos e ao entendimento de que nenhuma formação é "acabada" o suficiente para se restringir a um único período de estudos; ou seja, uma graduação não é o suficiente para se aprofundar nos conteúdos ou entrar em contato com a maior quantidade de assuntos possível. Isso ocorre porque a ciência se modifica constantemente, na medida em que os cientistas se aprofundam nas pesquisas a nível de pós-graduação e é importante que os demais profissionais conheçam as novas proposições teóricas da sua área e as atuais demandas educacionais. Além da modificação no campo teórico da formação, existem também as modificações sociais, políticas e econômicas, que interferem diretamente no mecanismo dos processos formativos e exigem um profissional preparado para 
lidar com elas - o que não é possível se eles não se mantiverem em formação, seja por meio da troca de experiências com outros profissionais da área, seja pela participação em grupos de pesquisa seja em cursos de capacitação.

Para que essa atualização seja constante e recorrente, é necessário haver incentivo nos níveis municipais, estaduais e federais, mas o mesmo só ocorre se estiver regulamentado legalmente. Pensando nisso, buscamos na Lei de Diretrizes e Bases 9.396/96 - legislação que rege o sistema de educação no Brasil - capítulos que versassem sobre formação continuada. No âmbito da docência, especificamente - que é o assunto do qual trata este artigo -, o capítulo IV da Seção V, intitulado “Da educação superior", afirma que é função da educação superior possibilitar a formação inicial (graduação) bem como colaborar com a formação continuada. Mais a frente, no Título VI "Dos profissionais da educação", o parágrafo primeiro do Art. 62 garante que a União, o Distrito Federal, os Estados e Municípios devem promover a formação inicial e a continuada e, no parágrafo segundo, a formação continuada e capacitação dos profissionais de magistério constam como possíveis de serem submetidas à educação a distância.

As informações constantes na legislação geram reflexões no campo da exequibilidade das garantias. As leis autorizam e garantem a formação continuada, mas a sua aplicação fica a critério dos estados, municípios e instituições. Além disso, a falta de detalhes na Lei ameniza a eficácia da promessa, interferindo em sua aplicabilidade e qualidade, visto que os critérios de execução, a regularidade do curso e demais detalhes não são fornecidos e especificados, deixando a cargo do feitor do trabalho.

Além da LDB, aprofundamos a análise estudando o Plano Nacional da Educação (PNE) de 2014, cujas metas são traçadas em uma perspectiva de 10 anos, ou seja, as 20 metas definidas neste documento devem estar cumpridas até 2024. Como o objetivo deste artigo é olhar para as políticas de formação para a educação continuada, destacaremos as metas que tenham enfoque sobre isso. 
A partir da meta 14 até a 16 encontramos determinações à respeito da formação inicial e continuada no Brasil, de modo direto ou indireto. Na redação da meta, além da explicação e apresentação de dados comprobatórios, são apresentadas as estratégias que serão utilizadas para atingir o objetivo.

A meta 14 visa aumentar o número de matriculados na pósgraduação strictu sensu e, consequentemente, elevar o número anual de titulados. Para concretizá-la, buscarão aumentar o financiamento das pós-graduações, ampliar a oferta de programas de pós-graduação e afins.

A meta 15 pretende instaurar a política de formação específica (em licenciaturas ou cursos específicos) dos profissionais da educação básica. Uma das estratégias para atingir essa meta é a reformulação curricular das licenciaturas e a articulação entre a formação universitária e as exigências da educação básica.

Em relação à meta 16, objetiva-se ampliar, até 2024, o número de profissionais com pós-graduação a cinquenta por cento a mais do número atual, garantindo "[...] a todos(as) os(as) profissionais da educação básica formação continuada em sua área de atuação, considerando as necessidades, demandas e contextualizações dos sistemas de ensino" (BRASIL, 2014, p. 12). O PNE atesta que este trabalho, na qualidade do padrão educacional, se orienta a partir de "[...] investimentos que o poder público e a sociedade façam no tocante à valorização e ao aprimoramento da formação inicial e continuada dos profissionais da educação" (p. 51).

Da mesma maneira, é importante que existam medidas que beneficiem os professores no processo de capacitação gerando bonificações salariais e planos de carreira "[...] de modo a garantir condições para a realização satisfatória dessa formação" (p. 52), visando o aperfeiçoamento desses profissionais em suas áreas de formação e atuação e em relação às mudanças no meio escolar.

Ainda sobre a meta 16, entende-se que deve haver "[...] esforços articulados dos entes federativos para dimensionar a demanda por formação continuada e promover a respectiva oferta por parte das instituições públicas" (p. 51). A menção, elencada como uma das estratégias para o cumprimento da 
meta, dialoga com a discussão do presente artigo referente à precariedade das ofertas de formação continuada e as lacunas apresentadas na legislação. Como pudemos perceber nos trechos destacados da LDB, a garantia da formação continuada apresentada na lei de forma pouco delineada permite que hajam lapsos no seu planejamento; desta forma, se faz necessário que o poder público atue ativamente no processo estrutural da formação continuada no Brasil e mantenha viva a discussão e a concretização da mesma. Não basta estabelecer um prazo e um resultado a ser atingido quando não se sabe claramente o caminho que precisa ser percorrido para alcançá-lo, ou seja, existe uma data limite, uma meta a ser alcançada, mas não se estabeleceu um planejamento coerente para aproximar o campo real do ideal.

Após realizar a leitura das Diretrizes Curriculares Nacionais para Educação Básica (DCN), notamos que é predominante a comprovação das contribuições da formação continuada para os docentes atuantes, auxiliando na educação infantil, EJA, educação especial, quilombola e até mesmo na reflexão sobre os direitos humanos no contexto escolar. Além disso, há orientação na formulação e no manejo dos cursos de formação inicial e continuada dos profissionais da educação básica.

[...] no exercício da docência, a ação do professor é permeada por dimensões não apenas técnicas, mas também políticas, éticas e estéticas, pois terão de desenvolver habilidades propedêuticas, com fundamento na ética da inovação, e de manejar conteúdos e metodologias que ampliem a visão política para a politicidade das técnicas e tecnologias, no âmbito de sua atuação cotidiana (DCN, 2013, p. 59).

Essa perspectiva nutre o papel da formação continuada no processo de atuação do profissional da educação, visto que a escola, as metodologias de ensino-aprendizagem, a política e, sobretudo, a sociedade, estão em constante processo de construção. Além disso, compreendemos que a complexidade da atuação de um professor/professora se estende à quantidade de estudantes, às características econômicas/sociais da turma, ao 
período e faixa etária em que os alunos se encontram, ao espaço físico de trabalho, aos aspectos culturais da região, dentre outros fatores. Segundo Gomes e Santos, "A reflexão sobre o cotidiano, sobretudo a partir das dúvidas reais do professor, para além de sua tarefa, para além de si mesmo, constitui-se na condição para que se proceda uma formação mais articulada e coerente com a realidade" (2004, p. 4). Neste sentido, são apresentadas algumas determinações que repercutem diretamente no trabalho e na formação deste profissional:

Para a formação inicial e continuada dos docentes, portanto, é central levar em conta a relevância dos domínios indispensáveis ao exercício da docência, conforme disposto na Resolução CNE/CP n 1/2006, que assim se expressa: I - o conhecimento da escola como organização complexa que tem a função de promover a educação para e na cidadania; II - a pesquisa, a análise e a aplicação dos resultados de investigações de interesse da área educacional; III - a participação na gestão de processos educativos e na organização e funcionamento de sistemas e instituições de ensino. Além desses domínios, o professor precisa, particularmente, saber orientar, avaliar e elaborar propostas, isto é, interpretar e reconstruir o conhecimento. Deve transpor os saberes específicos de suas áreas de conhecimento e das relações entre essas áreas, na perspectiva da complexidade; conhecer e compreender as etapas de desenvolvimento dos estudantes com os quais está lidando. [...] Tal proposição implica um redimensionamento dos cursos de licenciaturas e da formação continuada desses profissionais (p. 58).

Diante do que foi mencionado, pudemos identificar que há, nos documentos legislativos referentes à educação no Brasil o reconhecimento da necessidade da formação continuada no processo formativo do profissional da educação, contudo os mesmos documentos pouco se responsabilizam pelo modo com que esta atividade será efetivada. Estratégias foram determinadas, de fato, mas são espaçadas e genéricas, o que mantém um caráter impreciso. Não são delimitados números mínimos de ofertas para cada secretaria de educação, nem exigências de 
carga horária anual para cada docente e nem mesmo um tópico que garanta a constância da mesma.

Tendo em vista as legislações analisadas, compreendemos que muitos comportamentos das professoras participantes, apontados no decorrer da oficina, são reflexos de um sistema muito maior, ou seja, elas não dão a devida importância e credibilidade à formação continuada, porque as instâncias superiores não o fazem primeiro. Para corrigir esse equívoco, a mudança deve ocorrer na raiz do problema, para que assim tudo o que se desenvolve a partir dele seja também atingido e modificado.

Assim, a oficina desenvolvida, aplicada e analisada buscou apresentar metodologias possíveis que contemplem a prática teatral nos trabalhos desenvolvidos em sala de aula, de modo que dialogassem com o respectivo conhecimento prévio dos e das professoras do Ensino Básico, visando um processo críticoreflexivo por parte dos docentes para a devida articulação com os conteúdos ministrados. Tendo em vista a existência de políticas públicas pouco adequadas para se tratar dessa especificidade educacional, entendemos que há um longo caminho a ser percorrido para obtermos um programa de formação continuada eficiente que garanta aos profissionais da educação a oferta de cursos - conforme está descrito na legislação - que visem e possibilitem a melhoria efetiva do sistema de ensino no que tange a atuação do docente.

\section{CONSIDERAÇÕES FINAIS}

A oficina de formação continuada de professores dos centros de educação infantil, analisada neste artigo, teve como objetivo apresentar e experienciar possibilidades metodológicas do campo teatral a serem levadas à sala de aula. Para isso, levamos autores distintos e propostas que caminham desde jogos para crianças até o jogo como reflexão social, possibilitando às participantes conhecer e experimentar na prática diferentes aspectos do jogo dramático e teatral, 
perpassando por métodos e práticas distintas. A partir disso, elas teriam liberdade para selecionar e adaptar o que levariam às suas respectivas salas de aula. A metodologia utilizada exigia participação ativa em nossos planejamentos, pois defendemos que não é possível conhecer efetivamente as propostas de jogo de teatro apenas lendo ou ouvindo sobre elas, é necessário vivenciá-las. Fazê-las. Defendemos, também, que essa prática se realize de forma divertida e prazerosa, possibilitando a expressão de todo o grupo e relacionando com a sua realidade profissional e social.

As questões trazidas para análise neste artigo foram, especificamente, duas situações inesperadas, a saber: o interesse por materiais replicáveis e o comportamento imaturo do grupo durante as atividades. Ao buscar autores com os quais pudéssemos dialogar a respeito dessa temática, identificamos outras discussões sobre a desvalorização da formação e os impactos negativos que essas consequências traziam para o ensino regular. Por conta disso, decidimos buscar uma definição oficial nas legislações vigentes para a Educação a respeito da formação continuada e as determinações para fazê-la ser efetivada. Ao analisarmos os documentos (DCN, LDB e PNE), compreendemos que a raiz do problema é estrutural, ou seja, todas as "adversidades" das quais nos queixamos no início deste trabalho não eram dificuldades particulares e exclusivas daquele grupo em específico, mas o reflexo da desvalorização da profissão docente decorrente da má elaboração das políticas públicas vigentes.

A partir disso, pudemos concluir que a busca por materiais replicáveis é resquício de um ensino tecnicista e imediatista, voltado mais para os resultados do que para os processos de ensino e aprendizagem. O segundo tópico de análise, sobre a postura de aparente desinteresse, por vezes observada durante as oficinas, pode ser lido, em parte, como resultado do pouco incentivo (moral e financeiro) que se atribui à formação continuada ou da falta de compreensão da importância deste trabalho para a melhoria dos processos na sala de aula. Em 
ambos os casos, parte das conclusões esbarram na mesma questão: se houvessem políticas públicas elaboradas de modo sistemático e pontual, possivelmente os cursos de formação continuada teriam mais recorrência, sentido (para os participantes) e resultados efetivos na mediação entre a teoria e a prática em sala de aula. 


\section{REFERÊNCIAS}

BOAL, Augusto. Jogos para atores e não atores. Cosac Naify: São Paulo, 2015, 320 p.

BRASIL, Plano Nacional de Educação (PNE). Ministério da Educação / Secretaria de Articulação com os Sistemas de Ensino (MEC/ SASE), 2014.

BRASÍLIA, Diretrizes Curriculares Nacionais Gerais da Educação Básica (DCN)/ Ministério da Educação. Secretaria de Educação Básica. Diretoria de Currículos e Educação Integral. MEC, SEB, DICEI, 2013.

BRASÍLIA, Lei de Diretrizes e Bases da Educação Nacional (LDB). 10 edição. 2014.

DIAS, Cristina Rocha. A função do professor com crianças pequenas: impasses frente ao enigma do infantil no contexto escolar. Dissertação de Mestrado, São Paulo: Instituto de Psicologia da Universidade de São Paulo, Universidade de São Paulo, 2014, 117 f.

LÜDKE, Menga; DA CRUZ, Giseli Barreto. Aproximando universidade e escola de educação básica pela pesquisa. Cadernos de pesquisa, v. 35, n. 125, p. 81-109, 2005.

RANGEL, Danuza da Cunha. PLETITSCH, Vera Lucia. Formaçâo de professores de Artes Visuais e educaçâo continuada. Danuza da Cunha Rangel. 2012. UENF.

RYNGAERT, Jean Pierre. Jogar, representar. São Paulo: Cosac Naify, 2009.

SANTOS, Fabiane Konowaluk. GOMES, Kelinês Cabral. O professor... de quem estamos falando mesmo?. PUCRS. 2004.

SARDELICH, Maria Emilia. Formação inicial e permanente do professor de arte na Educação Básica. Cadernos de pesquisa, n. 114, p. 137-152, novembro/2001.

SCHEIBE, Leda. Valorização e formação dos professores para a educação básica: questões desafiadoras para um novo plano nacional de educação. Educação \& Sociedade, Campinas, v. 31, n. 112, p. 981 1000, jul.-set. 2010.

SLADE, Peter. O jogo dramático infantil. São Paulo: Summus, 1978.

SPOLIN, Viola. Improvisação para o Teatro. São Paulo: Perspectiva, 2010. 